Federal Reserve Bank of Minneapolis

Research Department

\title{
Seasonal Solow Residuals and Christmas: A Case for Labor Hoarding and Increasing Returns
}

\author{
R. Anton Braun and Charles L. Evans*
}

Working Paper 575D

October 1996

\begin{abstract}
In aggregate unadjusted data, measured Solow residuals exhibit large seasonal variations. Total Factor Productivity grows rapidly in the fourth quarter at an annual rate of 16 percent and regresses sharply in the first quarter at an annual rate of -24 percent. This paper considers two potential explanations for the measured seasonal variation in the Solow residual: labor hoarding and increasing returns to scale. Using a specification that allows for no exogenous seasonal variation in technology and a single seasonal demand shift in the fourth quarter, we ask the following question: How much of the total seasonal variation in the measured Solow residual can be explained by Christmas? The answer to this question is surprising. With increasing returns and time varying labor effort, Christmas is sufficient to explain the seasonal variation in the Solow residual, consumption, average productivity, and output in all four quarters. Our analysis of seasonally unadjusted data uncovers important roles for labor hoarding and increasing returns which are difficult to identify in adjusted data.

JEL Classifications: 131, 023

*Braun, Federal Reserve Bank of Minneapolis; Evans, Federal Reserve Bank of Chicago. We thank Marty Eichenbaum, Jim Hamilton, Bob Chirinko, Julio Rotemberg, and Jim Nason for helpful comments. The views expressed herein are those of the authors and not necessarily those of the Federal Reserve Bank of Minneapolis or the Federal Reserve System.
\end{abstract}




\section{Introduction}

Prescott (1986) has argued that the variability of Solow's residual is a reasonable estimate of the variability of exogenous technology shocks. When Solow's residual is measured using seasonally unadjusted data for the postwar U.S. economy, it exhibits large seasonal variations, growing rapidly in the fourth quarter at an annual rate of 16 percent and falling sharply in the first quarter at an annual rate of -24 percent. This paper starts from the premise that it is implausible to attribute seasonal variation of this magnitude to changes in the state of technology. We present a model in which all seasonal fluctuations arise from a single demand shift, Christmas. This demand shift together with misspecification of the traditional production function leads to large seasonal variation in the Solow residual. We consider two candidates for misspecification, labor hoarding and external increasing returns to scale. Even when technological growth is aseasonal, either candidate in isolation can induce spurious seasonality in the Solow residual. Our general equilibrium analysis indicates

that: (1) the economy's seasonal patterns in all four quarters may be a response simply to a fourth quarter consumption demand shift, and (2) a combination of labor hoarding and external increasing returns are important for replicating these patterns in aggregate quantity variables for the postwar U.S. economy. Since our analysis identifies important roles for labor hoarding and increasing returns, these results have implications for nonseasonal macroeconomic models.

By focusing on seasonal fluctuations, our evidence complements the existing literature that considers features of the aggregate production technology. The existing literature is multifaceted. First, the literature on strategic complementarities (see for example, Cooper and Haltiwanger 1992) finds that production bunching can be due either to nonconvexities in the production technology or the arrival of technology shocks in bunches. In the latter case the technology could be constant returns to scale. Second, recent studies of empirical production functions find evidence that manufacturing production exhibits constant returns to scale. Burnside, Eichenbaum and Rebelo (1995) and Burnside (1996) report that accounting for variations in capital utilization leads to the inference that manufacturing production is constant returns to scale. Alternatively, Basu and Fernald (1995) suggest that aggregation biases may be cyclical, also leading to a conclusion that the production technology is con- 
stant returns to scale. Third, a number of authors have found that labor hoarding can help explain procyclical total factor productivity (see Rotemberg and Summers 1990 or Burnside, Eichenbaum and Rebelo 1993).

Seasonal fluctuations offer valuable identifying restrictions that can help identify the structure of the aggregate production technology. Barsky and Miron (1989) have argued persuasively that Christmas induces a large fourth quarter demand shift for the U.S. economy. Since output and consumption increase strongly without a corresponding increase in labor and capital, Barsky and Miron conclude aggregate supply is relatively elastic and labor hoarding is likely. ${ }^{1}$ On the other hand, it is difficult to identify bonafide seasonal shifters of technology. The contention that weather is an important seasonal impulse is weakened considerably by Beaulieu and Miron's (1992) finding that seasonal patterns in Southern Hemisphere countries resemble patterns in the U.S. Together our assumptions that technology is aseasonal and that Christmas is an important shift in demand provide identifying restrictions that have strong discriminatory power. ${ }^{2}$

Modeling seasonal fluctuations with a single Christmas demand shift requires us to model economic agents' responses to anticipated and transitory impulses. First, the anticipated nature of the Christmas seasonal shift leads us to model variations in labor effort as driven by convex costs of adjusting employment. Burnside, Eichenbaum and Rebelo (1993) model labor hoarding by assuming that employment is fixed at the beginning of the period and only labor effort can respond within a period to shocks. In their framework labor effort responds only to unanticipated shocks, exhibiting no noticeable persistence. ${ }^{3}$ To induce seasonal labor hoarding, the costs of adjusting quasi-fixed factors must be modeled explicitly. Second, the transitory nature of seasonal shifts leads us to consider convex costs of adjusting capital. In an economy with external increasing returns, Baxter and King (1990) found a negligible response of output to a purely transitory increase in consumption demand: consumption rose but investment fell, leaving output unchanged. In the absence of adjustment costs, a similar result is to be expected for the case of a fourth quarter Christmas seasonal. If increasing returns is to have a chance, it must be costly to adjust investment. Third, the nontime-separable preferences emphasized by Kydland and Prescott (1982), Eichenbaum, Hansen, and Singleton (1989), and others for business cycle variability also play an important 
role in propagating the Christmas demand shock beyond simply the fourth quarter. Thus, modeling seasonal fluctuations leads to a specification that incorporates the same propagation mechanisms that receive wide attention in models of the business cycle.

Many of the model's parameters governing returns to scale, the magnitude of adjustment costs and elasticities for work effort are difficult to pin down on a priori grounds. A Generalized Method of Moments (GMM) estimation strategy is used to produce estimates of these parameters. These estimates are then used to evaluate the seasonal growth rates implied by the model. We find that both labor hoarding and increasing returns mechanisms are important for capturing the U.S. economy's seasonal fluctuations. For each of the real variables in the model, the hypothesis that the predicted seasonal fluctuations match the data's seasonals cannot be rejected. The estimated parameterization proves to be remarkably successful at capturing the seasonal pattern in the measured Solow residual as well as the seasonal pattern in output, consumption, and average productivity. Results reported in Section 5 suggest further that labor hoarding and nontime-separabilities play the biggest role in propagating the Christmas demand shock. Increasing returns prove to be important for amplifying the seasonal patterns generated by the other features of the model.

An outline of the remainder of the paper follows. In Section 2 the model is described and the seasonal equilibrium growth path is defined. Section 3 contains a description of the data, the estimation strategy and a summary of the estimation results. Section 4 evaluates the seasonal implications of the estimated parameterization. Section 5 explores the separate roles played by labor hoarding and increasing returns in the analysis. Section 6 discusses some limitations of our analysis. In Section 7 we conclude by summarizing our results.

\section{The Economic Model}

In this section we describe the model economy. The presentation of the economy leads naturally to an optimization problem whose solution is the competitive equilibrium allocation. This solution is not Pareto optimal due to a productive externality. As we pose the problem, the planner does not take account of the externality. A benevolent social planner could do better by allowing agents to coordinate. This strategy for calculating competitive allocations in distorted economies is discussed at length in Romer (1988). 


\section{Preferences}

The household's period preferences depend upon consumption services $c_{t}^{*}$, leisure services $l_{t}^{*}$, and (negatively upon) the intensity of labor effort $v_{t}$. The period utility function is:

$$
\tau_{t} \log c_{t}^{*}+\alpha \log l_{t}^{*}-\frac{\xi}{2}\left(v_{t}-\bar{v}\right)^{2}, \quad \xi>0, \alpha>0
$$

where $\tau_{t}$ is a seasonal preference shifter. The preference shifter captures the household's increased desire to consume during the Christmas season:

$$
\tau_{t}=\bar{\tau} Q_{1 t}+\bar{\tau} Q_{2 t}+\bar{\tau} Q_{2 t}+\tau_{4} Q_{4 t}, \tau_{4}>\bar{\tau}>0
$$

where $Q_{i t}$ is a quarterly seasonal dummy variable taking on the value of 1 when period $t$ corresponds to season $i$ and zero otherwise. Consumption and leisure services are defined as follows:

$$
\begin{aligned}
& c_{t}^{*}=c p_{t}+a c p_{t-1}, \quad|a|<1 \\
& l_{t}^{*}=T-n_{t}+b\left(T-n_{t-1}\right), \quad|b|<1
\end{aligned}
$$

where $c p_{t}$ is consumption expenditures and $T$ represents the total time allocation. If $a>$ 0 consumption expenditures have a durable quality and are substitutable across adjacent periods. If $a<0$ consumption expenditures are complements across adjacent periods, and consumption preferences exhibit habit persistence. The same interpretations hold for $b$ and leisure preferences.

The specification of preferences over labor effort is a quadratic approximation to a nonlinear function; specifically, $\bar{v}$ is estimated to be negative and $\xi$ determines the slope of the marginal disutility of labor effort. ${ }^{4}$ Notice that leisure and work effort enter asymmetrically in both preferences and technology (below). An asymmetry is necessary for economic agents to vary labor's input along both the extensive margin $n_{t}$ and the intensive margin $v_{t}$.

\section{Production}

The representative household has access to a technology which produces goods $(y)$ using capital $(k)$, labor hours $(n)$, and labor intensity $(v)$ :

$$
y_{t}=\phi_{t} k_{t}^{\theta}\left(z_{t} n_{t} v_{t}\right)^{1-\theta} J_{t}, \quad 0<\theta<1
$$




$$
\begin{aligned}
z_{t} & =z_{t-1} \exp \left(\lambda+\varepsilon_{t}\right) \\
\phi_{t} & =\phi_{1}\left(\bar{y}_{t} / z_{t}\right)^{\phi_{2}}, \phi_{1}, \phi_{2}>0
\end{aligned}
$$

Aside from the choice of factor inputs $k, n$, and $v$, the level of production is influenced by three additional factors: exogenous variation in the state of technology $z_{t}$, a productive externality $\phi_{t}$, and convex adjustment costs $J_{t}$ on capital and labor (with the specification described below). Each of these factors will now be discussed separately.

The technology variable $z_{t}$ is a random walk process in logarithms with constant drift $\lambda$. The impulse $\varepsilon_{t}$ is an independent, serially uncorrelated random variable. Three observations on the role of $z_{t}$ in our analysis are noteworthy. First, the constant drift term $\lambda$ is nonseasonal - this is our identifying restriction that the true technology is aseasonal. Second, all growth in this economy originates with $z_{t}$ since our specification of the productive externality exhibits local increasing returns (discussed below). In the balanced growth equilibrium that we analyze, therefore, all trending variables share the same trend as $z_{t}$. Third, the variability of $\varepsilon_{t}$ plays no role in our analysis of perfect foresight seasonal growth paths, but its presence satisfies a necessary condition for our econometric relationships to be well-posed in Section 3.

Increasing returns in production are captured by the Marshallian externality variable $\phi_{t}$, where $\bar{y}_{t}$ represents the economy-wide level of per capita output. Marshallian productive externalities have been considered by Bryant (1983), Murphy, Shleifer, and Vishny (1989), Caballero and Lyons (1992), Baxter and King (1990), and Cooper and Haltiwanger (1996). We follow the strategic complementarities literature (see Cooper and Haltiwanger for a survey) which essentially views equations (5) and (7) as a reduced form for a more complicated market structure. For example, in models with search and matching such as Diamond (1982) and Howitt (1985), high levels of economic activity make it easier to find a trading partner and reduce transactions costs. This is one interpretation of our productive externality mechanism. Formally integrating these non-Walrasian elements into business cycle models remains an open topic for further research. In our framework, the representative household is too small to influence the economy-wide output, so $\phi_{t}$ is taken to be beyond the household's control. Since the externality is expressed relative to the level of technology $z_{t}$, this 
specification embodies local increasing returns - as aggregate economic activity rises relative to trend, the economy becomes more productive. ${ }^{5}$

The variable $J_{t}$ is a factor which relates to the cost of adjusting capital and labor hours in terms of lost output:

$$
J_{t}=\exp \left\{-\frac{\psi_{1}}{2}\left(\frac{k_{t+1}-k_{t} \exp \left(\lambda+\varepsilon_{t}\right)}{k_{t}}\right)^{2}-\frac{\psi_{2}}{2}\left(\frac{n_{t}-n_{t-1}}{n_{t-1}}\right)^{2}\right\}
$$

where $\psi_{1}$ and $\psi_{2}$ are positive, and $\lambda$ is the average growth rate of capital as well as the technology $z_{t}$. The first term states that it is costly to increase the capital stock at a rate other than its average growth rate. The firm has in place a technology for assimilating new capital into the production process. This technology costlessly accepts the normal level of new investment, but other levels create congestion in the production process. Likewise, the second term states that it is costly to increase labor hours at a rate other than its unconditional growth rate, which is zero. For this specification, the adjustment cost factor $J_{t}$ is in the interval $(0,1]$ and in a nonseasonal steady state $J_{t}=1 .^{6}$

\section{Period Budget Constraint}

The household's period budget constraint is given by:

$$
\phi_{t} k_{t}^{\theta}\left(z_{t} n_{t} v_{t}\right)^{1-\theta} J_{t}=c p_{t}+k_{t+1}-(1-\delta) k_{t}
$$

where $\delta$ is the rate of capital depreciation per quarter. Fiscal policy could be introduced into the model and constraint (9) (as in Braun and Evans 1995), but our focus in this paper is the single demand seasonal Christmas since that is a relative constant across countries.

\section{Planner's Problem}

The competitive equilibrium allocations in a decentralized version of this economy are identical to the solution of the following optimization problem. ${ }^{7}$ At time 0 , choose a sequence of contingencies $\left\{c p_{t}, n_{t}, v_{t}, k_{t+1} ; t \geq 0\right\}$ to solve the following:

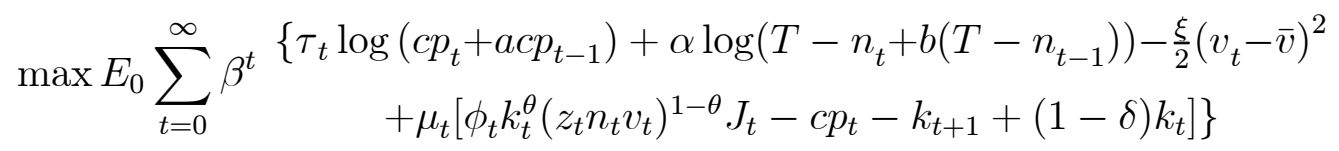

where $\mu_{t}$ is a Lagrange multiplier, and the initial values $k_{0}, c p_{-1}$, and $n_{-1}$ are given. Notice that the planner ignores the productive externality, treating $\phi_{t}$ as given: while this is 
suboptimal, it is the analogous problem to the one faced by small households and firms. It is well-known that the optimal allocations which solve this problem are characterized by the first-order conditions for $c p_{t}, n_{t}, v_{t}, k_{t+1}$, and a transversality condition related to capital (for an example, see Braun and Evans 1995). Furthermore, assets can be priced using intertemporal marginal rates of substitution in the usual way.

\section{A Perfect Foresight Seasonal Equilibrium Growth Path}

This economy grows over time at the rate of exogenous technological progress which is given by $\lambda$ per period. Since preferences shift over the calendar year, however, these growth rates may vary seasonally. A perfect foresight seasonal equilibrium growth path

for this economy is a generalization of the standard definition of a balanced growth path. ${ }^{8}$ The relevant new feature is that the seasonal growth path is indexed by season. Thus, consumption in year $t$ and quarter $i$ is linked to consumption in year $t+1$ quarter $i$ by the following relationship: $c_{t+1, i}=e^{4 \lambda} c_{t, i}$. Along the seasonal growth path, consumption will always grow $x_{1}$ percent in the winter, $x_{2}$ percent in the spring, $x_{3}$ percent in the summer, and $x_{4}$ percent in the fall. ${ }^{9}$

\section{Seasonality in Measured Solow Residuals}

Suppose that a researcher attempts to measure Solow residuals for this economy as Prescott (1986) does. Armed with the precise knowledge of $\theta$, the measured Solow residual will be: ${ }^{10}$

$$
\begin{aligned}
S_{t} & \equiv\left[\Delta \log y_{t}-\theta \Delta \log k_{t}-(1-\theta) \Delta \log n_{t}\right] /(1-\theta) \\
& =\left[\left(1-\theta-\phi_{2}\right) \Delta \log z_{t}+\phi_{2} \Delta \log y_{t}+(1-\theta) \Delta \log v_{t}+\Delta \log J_{t}\right] /(1-\theta)
\end{aligned}
$$

Assuming that the deterministic component of technological growth $\left(z_{t}\right)$ is aseasonal, then seasonality in $S_{t}$ can arise from: (1) increasing returns if output is seasonal, (2) labor hoarding if variations in labor effort are seasonal, and (3) seasonal adjustments in capital and labor hours. If the fourth quarter increased desire to consume is strong enough to generate a seasonal increase in fourth quarter output, then measured Solow residuals will be proseasonal due to the productive externality. If the higher output is achieved by a seasonal increase in 
work effort (without a correspondingly large increase in adjustment costs), then the demand effect is reinforced. ${ }^{11}$ Whether or not a single Christmas seasonal in preferences can explain seasonality in Solow residuals, in all four quarters, depends upon the model's ability to generate seasonality in output and labor effort across the entire calendar year.

\section{Econometric Estimation of the Model's Structural Parameters}

The vector of structural parameters $\psi$ contains 16 elements:

$$
\psi=\left(\delta, \beta, T, \bar{\tau}, \tau_{4}, \alpha, a, b, \xi, \bar{v}, \theta, \psi_{1}, \psi_{2}, \lambda, \phi_{1}, \phi_{2}\right)
$$

In assigning parameter values, there are three categories of parameters: (1) parameters which can be normalized a priori because their values have no influence upon the analysis; (2) parameters which are customarily set a priori because their values are not well-identified in the data; and (3) parameters which are econometrically estimated by Generalized Method of Moments. First, the parameters $\left(\alpha, T, \phi_{1}, \bar{v}\right)$ are inherently unidentified. Since utility is ordinal, we normalize $\alpha=1$ and estimate the consumption preference parameters $\bar{\tau}$ and $\tau_{4}$. The time allocation is set to $T=1369$ hours per quarter (as in Christiano and Eichenbaum 1992). Labor effort $v_{t}$ is an index variable whose level depends upon $\bar{v}$ : we set $\bar{v}$ at a level which guarantees that average labor effort will be $1 .{ }^{12}$ The parameter $\phi_{1}$ simply defines the units of measure for commodities (thousands of dollars, billions of yen, etc.): its value can be selected arbitrarily without affecting the analysis. Second, the discount factor $\beta$ is not well-identified in aggregate time series data. We set $\beta$ equal to $1.03^{-.25}$ as in Christiano and Eichenbaum. Third, the lack of seasonally unadjusted quarterly data on the capital stock leads us to construct capital from investment flows assuming that the depreciation rate $\delta$ is 2.5 percent per quarter. The remaining parameters are econometrically estimated by Generalized Method of Moments.

\section{A. GMM Estimation}

The parameters $\left(\theta, \bar{\tau}, \tau_{4}, \psi_{1}, \psi_{2}, a, b, \lambda, \phi_{2}, \xi\right)$ are estimated by imposing jointly two sets

of moment conditions: (1) orthogonality conditions based upon the household's intratemporal Euler equation for choosing consumption and leisure; and (2) explicitly equating a set of first moments in the data with the model's predictions for these moments. For the first set of 
moments, the Euler equation can be written (in terms of observables) as:

$$
\begin{aligned}
& \mu_{t}\left[(1-\theta) \frac{y_{t}}{n_{t}}-\psi_{2} \frac{y_{t}}{n_{t-1}}\left(\frac{n_{t}}{n_{t-1}}-1\right)\right]+\beta E_{t}\left[\mu_{t+1} \psi_{2} \frac{y_{t+1} n_{t+1}}{n_{t-1}^{2}}\left(\frac{n_{t+1}}{n_{t}}-1\right)\right] \\
& -\left(\left(T-n_{t}\right)+b\left(T-n_{t-1}\right)\right)^{-1}-b \beta\left(\left(T-n_{t+1}\right)+b\left(T-n_{t}\right)\right)^{-1} \\
= & 0
\end{aligned}
$$

where $\mu_{t}=\tau_{t} /\left(c p_{t}+a c p_{t-1}\right)$. Any variable in the time $t$ information set is a valid instrument for estimating the parameters in this equation. The instrument set includes the time $t$ and $t-1$ growth rates $\left(x_{t} / x_{t-1}\right.$ and $\left.x_{t-1} / x_{t-2}\right)$ of labor hours, capital, consumption, and output, as well as four seasonal dummy variables.

To describe the second set of moment restrictions, let $H\left(x_{t}\right)$ refer to the following transformations of the data:

$$
H\left(x_{t}\right)=\left[\left(\triangle \log y_{t}\right) q_{t}^{\prime}\left(\triangle \log c p_{t}\right) q_{t}^{\prime}\left(\triangle \log y_{t} / n_{t}\right) q_{t}^{\prime}\left(\triangle \log k_{t}\right) q_{t}^{\prime}\left(\Delta \log \left(1+r_{t}\right)\right) q_{t}^{\prime} k_{t} / y_{t} n_{t}\right]^{\prime}
$$

where $q_{t}$ is a $4 \times 1$ vector of seasonal dummies, $r_{t}$ is a real interest rate, and the symbol ' denotes transposition, so $H\left(x_{t}\right)$ is a $22 \times 1$ vector. $^{13}$ Accordingly, the first 20 elements of the expected value of $H\left(x_{t}\right)$ are the seasonal growth rates of output, consumption, labor productivity, and capital, and the seasonal change in the real interest rate. The last two elements correspond to the average capital-output ratio and average labor hours. Given this definition, the model predicts that

$$
H\left(x_{t}\right)=h(\psi)+u_{t}
$$

where $h(\psi)$ corresponds to the model's predicted first moments of $H\left(x_{t}\right)$ and $u_{t}$ is a vector mean zero, serially correlated random variable. Based upon these moment restrictions, our estimator of $\psi$ attempts to set the sample mean of $u_{t}$ to zero, as well as the sample moments based upon equation (12).

Our choice of moment restrictions is motivated by two concerns. First, since labor effort is unobserved, the parameter $\xi$ cannot be estimated by Euler equation methods. Second, estimating $\phi_{2}$ from production function residuals seems hopeless due to the presence of unobserved variations in labor effort: no exogenous instruments are available. ${ }^{14}$ However, 
these parameters can be estimated by forcing the model to confront the seasonal growth rates in the data by choosing $\phi_{2}$ and $\xi$, as well as the other parameters.

Finally, Sims (1993) and Hansen and Sargent (1993) have argued that econometricians who use seasonally unadjusted data and misspecify the seasonal mechanisms may do much worse than econometricians who discard the potential information content at seasonal frequencies and simply use seasonally adjusted data. On the other hand, Ghysels (1991) has pointed out that great efficiency gains may be possible if seasonally unadjusted data is used. Thus, there is a potential trade-off involved in using seasonally unadjusted data, efficiency gains versus misspecification bias. We try to address the bias issue by comparing our parameter estimates with other econometric studies which used seasonally adjusted or annual data.

\section{B. Data}

The data set employed in this study is an updated counterpart to the Barsky-Miron (1989) data. This is U.S. quarterly data which has not been adjusted for seasonality and covers the sample period 1964-94. For the empirical analysis to conform to the theoretical constructs of our model, however, we redefine some of the variables as follows (and convert to per capita values). Output $(y)$ is Gross Domestic Product per capita. Private consumption $(c p)$ is nondurables plus services consumption expenditures per capita. Investment $(i)$ is the sum of Fixed Investment plus Durable consumption expenditures, per capita. The capital stock is computed using the flow investment expenditures, a quarterly depreciation rate of 2.5 percent, and an initial capital stock value for 1963. Labor hours are computed as the product of total nonagricultural employment times average hours per week of nonagricultural production workers times 13 weeks per quarter (per capita). The real interest rate is the ex post return on three-month Treasury Bills, not seasonally adjusted. The data is converted to per capita values by using the civilian population, 16 years and older.

\section{Estimation Results}

Table 1 presents our estimation results. The estimation imposes 34 moment restrictions in estimating 10 structural parameters; in principle, there are 24 overidentifying restrictions which are tested by Hansen's (1982) J-statistic. The statistic is 28.51 with a probability 
value of 0.24 , uncovering no evidence against these restrictions. Recall that 20 of the 34 restrictions involve matching the model's seasonal predictions against the data's seasonal growth rates. Informally, this diagnostic suggests that the model captures the data's seasonal properties. This claim is examined in more detail in Section 4 where we consider a variety of other tests that focus explicitly on the model's seasonal predictions.

Turning to the individual parameters, our estimates using seasonally unadjusted data are similar to other estimates in the literature which have employed seasonally adjusted data. Our estimate of $\theta$ is 0.279 which is close to Prescott's (1986) value of 0.25 (when output is identified with GNP and does not include the services of durable consumption goods). The weighted average value of $\bar{\tau}$ and $\tau_{4}$ is 0.2367 . The inverse $1 / \tau$ corresponds to the leisure preference parameters estimated by Christiano and Eichenbaum; our value of 4.22 falls within the range 3.92 and 5.15 they report. The Christmas consumption effect is estimated to be $\tau_{4} / \bar{\tau}=1.023$; this is the percentage increase in the marginal utility of consumption services, holding consumption services fixed. This value does not seem to be implausibly large.

The unusual precision of $\theta, \bar{\tau}$, and $\tau_{4}$ is due to the two moment restrictions in $H\left(x_{t}\right)$ which are related to the capital-output ratio and the level of labor hours. If these two moment conditions are dropped and $\psi$ is re-estimated, the parameter estimates are essentially unchanged, but the standard errors for $\theta, \bar{\tau}$, and $\tau_{4}$ rise to $0.0358,0.011$, and 0.011 , respectively. Therefore, the unusual precision of these parameter estimates is due to the inclusion of strong identifying restrictions from the model's equilibrium predictions.

The nontime-separability parameters $a$ and $b$ are similar to other researchers' estimates. The value of $a=0.442$ indicates that consumption goods have a durable quality: in seasonally adjusted data, this has been found by Eichenbaum, Hansen, and Singleton (1989) and Gallant and Tauchen (1989). ${ }^{15}$ Moreover, a positive value of $a$ also helps to propagate the Christmas demand shock across the other seasons. So in the first quarter, households have less urgency to purchase additional goods, following the high consumption in the previous quarter. ${ }^{16}$ The value of $b=-0.528$ indicates that leisure preferences exhibit habit-persistence: in seasonally adjusted data, this has been found by Eichenbaum, Hansen, and Singleton as well as Braun (1994). This feature makes leisure and labor hours relatively smooth; in addition to adjustment costs for labor hours, habit-persistence in leisure will smooth labor hours 
and lead to greater variations in labor effort in response to exogenous shocks.

The adjustment cost parameters are significantly different from zero. ${ }^{17}$ The capital and labor estimates are 27.66 and 0.238 , but these numbers are a poor indication of their relative effects. On a quarterly basis, the standard deviations for the growth rates of capital and labor are 0.49 percent and 2.18 percent. The percentage reduction in output due to adjusting capital (only) and labor (only) by one standard deviation above average is 0.03 percent and 0.006 percent. So the capital adjustment penalty is only about 3 times larger than the labor penalty. Also, these numbers indicate that the direct effect of adjustment costs on measured Solow residuals is negligible. That is, the effects of $\Delta \log J_{t}$ in equation (11) are small. As was noted in Section 2, however, the indirect effect may be large: in response to a consumption demand shock, reducing investment may now be costly enough to induce a large response in output.

Our estimate of the output elasticity with respect to external increasing returns is $\phi_{2}=0.217$. The elasticity is significantly different from zero. This value is within the range of estimates reported by Caballero and Lyons (1992) and Baxter and King (1990), although Baxter and King use a larger value of 0.33 in their model evaluation. The size and statistical significance of our estimate provides some evidence that external increasing returns are important for explaining seasonal fluctuations; a quantitative assessment is offered in Section 4. Nevertheless, since our identifying restrictions differ from those of CaballeroLyons (1992) and Baxter-King (1990), our estimate of $\phi_{2}$ provides evidence which is both independent of theirs and complementary.

It is interesting to compare our estimate of the returns to labor and capital with the benchmark economy-wide production function estimates in Burnside, Eichenbaum, and Rebelo (1995). Abstracting from adjustment costs in our production technology, our estimates of the returns to labor and capital can be computed by substituting out $\phi_{t}$ in equation (5), yielding $1 /\left(1-\phi_{2}\right)=1.277$. In their Table 2, Burnside, Eichenbaum, and Rebelo report their economy-wide estimate of the returns to labor and capital to be 0.98 with a standard error of 0.34. While their null hypothesis is constant returns to scale, it is interesting to note that their most general estimates are not significantly different from ours for the entire economy. When they impose additional functional restrictions on the substitutability of industrial electricity 
and the workweek of capital or focus on manufacturing, they find much stronger evidence of constant returns to scale. Although most of the evidence against increasing returns comes from the manufacturing sector, manufacturing is less than half of the aggregate economy. Our aggregate analysis covers a larger output concept than manufactured goods, so this could account for some of the discrepancy.

Our estimate of $\xi$ is 0.016 , so the disutility of labor effort deviations may in fact be small enough to induce sizable variations. The standard error is 0.0341 , so the estimate is reasonably imprecise. It is important to note that the hypothesis that variations in labor effort are small would imply that $\xi$ is large: the point estimate and standard error do not support this. As we will see in Section 4, estimates of $\xi$ in the range reported are capable of yielding substantial variations in work effort. Thus, the estimated habit-persistence in leisure preferences, costly adjustment of labor, and relatively small disutility associated with varying labor effort jointly provide evidence for the labor hoarding hypothesis. Finally, the value of $\bar{v}$ implied by the estimates and normalization is negative. Thus, utility is strictly decreasing in work effort.

Overall, the estimated parameterization seems reasonable. The similarity of many estimates with previous studies suggests that if we had chosen to "calibrate" our model using these other studies, the resulting parameterization would not have been very different. Finally, the overidentifying restrictions cannot be rejected.

\section{Evaluating the Model's Seasonal Implications}

In this section we evaluate the seasonal properties of the estimated parameterization and offer evidence on the relative importance of labor hoarding and increasing returns in explaining the seasonal patterns in the data. Two criteria are used to evaluate the model's seasonal predictions. First, a series of hypothesis tests are reported. These tests have the benefit of taking into consideration sampling error in the summary statistics for the data and sampling error in the estimated parameterization. Second, the seasonal growth rates of the data and the model are simply plotted together. This latter approach provides a visual summary of the seasonal properties of the model relative to the data.

Table 2 contains results from a series of hypothesis tests. The results in Table 2 are 
aimed at providing information on the following three questions: Is there evidence of seasonality in the data? Does the model predict significant seasonality? Does the model predict the same seasonal patterns found in the data? Column one reports Wald statistics that offer evidence on the first question for each variable individually. The maintained null underlying the column one results is that the four seasonal dummies for a particular time series are equal (equation (1), Table 2). These statistics are constructed from GMM estimates of the average seasonal growth rates in the data and use a Newey-West (1987a) covariance estimator. The $p$-values for each statistic indicate that the null hypothesis of no seasonality is overwhelmingly rejected for each time series. These results are representative of findings reported by Barsky and Miron (1989). ${ }^{18}$ Column two reports Wald statistics that offer evidence on the second question. The maintained null hypothesis is that the model's predicted seasonal growth rates are equal. ${ }^{19}$ The null hypothesis of no seasonality is also sharply rejected for each of the time-series that the model offers predictions for. On the basis of the results from these two tests, we conclude that both the model and the data offer strong refutable predictions at seasonal frequencies.

Certainly the most important question is the third one: Does the model predict the seasonal patterns in the data? Column three of Table 2 provides one metric for evaluating the model's "fit" at seasonal frequencies. The maintained null hypothesis in column three is that the model's predicted seasonal growth rates for the $j$ th time-series equal the corresponding values in the data in each of the four seasons. This LaGrange multiplier (or LM) test is formally a test of particular moment restrictions that were imposed in the course of estimation. For hours, the Solow residual, and investment, the statistics were calculated using the fact that these time series can be expressed as (log) linear combinations of other time series that were included in the estimation. Eichenbaum, Hansen and Singleton (1984) and Newey and West (1987b) describe the details of implementing LM tests in the context of GMM estimation. Column three contains surprisingly little evidence against the null of a common seasonal pattern in all instances. As a check we also calculated a GMM analog to the likelihood ratio statistic and found that the two statistics were virtually identical.

This collection of statistics provides two important conclusions. First, the tests reported in columns one and two demonstrate that the statistics have sufficient power to reject 
the null hypothesis of no seasonality for the model and the data. Second, the column three results find no evidence against the hypothesis that the model correctly predicts the pattern of seasonality found in the data.

Turning to the specific predictions of the model, we report plots of the seasonal growth rates for the data and model in Figure 1 (the estimated seasonals from the data and the model are presented in Table 3 along with their standard errors). These diagrams complement the previous hypothesis tests in that they offer summary information on the ability of the estimated parameterization to capture particular aspects of the seasonal pattern in the data. We will focus on two aspects of the seasonal pattern: the magnitude of the model's predicted seasonal in a particular quarter relative to the data and the ability of the model to mimic the sequential relationship of seasons found in the data. The Solow residuals labeled "data" are calculated using $\theta=0.279$. As was noted in Section 3 this number is qualitatively close to the value of 0.25 used by Prescott (1986).

One of the principal aims of this paper is to investigate the possibility that increasing returns and/or time-varying labor effort can explain the large seasonal variation in the Solow Residual. Figure 1 confirms the results reported in Table 2: the model is quite successful in this respect. The predicted Solow residual has the same sequential pattern and captures the magnitudes found in the data. These results offer support for our contention that the observed seasonal pattern in the Solow residual is driven largely by demand shocks.

In addition to capturing the seasonal pattern in the Solow residual, the model also mimics important features of seasonality in output, consumption and average productivity. In all of these instances the model correctly predicts the sequential seasonal pattern of the data. For consumption we do see a tendency for the model to overstate the third quarter deceleration found in the data and for output the model understates the second quarter rise. However, the hypothesis tests indicate that both of these disparities can be attributed to sampling error. ${ }^{20}$ These successes across the entire calendar year are particularly striking given that the only seasonal shifter is a fourth quarter shift in preferences.

Figure 1 also displays the seasonal patterns in labor effort. Since this is an unobservable, the data's seasonals cannot be reported. Fourth quarter output rises on the strength of higher than normal labor effort. In combination with increasing returns, fourth quarter effort 
is only 3 percent above normal in generating an annualized output growth of 13 percent. $^{21}$ Opposing forces are at work in the first quarter. These variations in effort do not seem implausible.

If we ignore sampling error, the figures suggest that the model fails to account for some aspects of the seasonal pattern in other variables. For hours, investment, and the capital stock, the magnitudes are off in all four quarters, and for interest rates they are off in two quarters. However, even for these time series the model captures some of the features of the sequential pattern in the data. The fact that the hypothesis tests in Table 2 fail to reject a common seasonal pattern in individual time series suggests that there may be considerable sampling error. The most likely sources for this sampling error are in $\hat{\xi}$ and

$\hat{\phi}_{2}$, parameters which govern respectively the roles of time-varying labor effort and increasing returns. Both parameters are estimated with sizable standard errors. The case analyses below demonstrate that variations in these two parameters lead to a deterioration in the model's seasonal predictions relative to the data.

\section{Case Analysis}

To explore the contribution of increasing returns and labor hoarding we estimated two constrained versions of the model. Column one of Table 4 reports results in which the increasing returns curvature parameter $\phi_{2}$ is set to zero. We will refer to this specification as the labor hoarding only specification. Column two of Table 4 reports results for the increasing returns only specification. Here the adjustment cost on labor input $\psi_{2}$ is set to zero and $\xi$ is chosen to be an arbitrarily large value. Since our baseline model nests each of these specifications, we can test the additional restrictions imposed by our increasing returns only and labor hoarding only. Tests of these restrictions are reported at the bottom of each column. Notice that each set of restrictions is sharply rejected by the data.

\section{A. Increasing Returns Only}

Consider Figure 2 which plots the seasonal patterns for the increasing returns only specification. These plots reveal a substantial deterioration in fit relative to the baseline model. The increasing returns only specification fails to capture the up-down pattern we see in measured output and labor productivity growth, and the Solow residual. This specifica- 
tion also totally fails to capture the seasonal pattern in investment growth, increasing when investment is down in the data and declining when investment is up in the data. On the other hand, the pattern of consumption growth in the model is very similar to that of the data.

To gain some intuition for the failure of the increasing returns only case, let's focus on the fourth quarter increase in Christmas demand. The increase in consumption demand places a lower value on leisure, so that labor supply increases (shifting out in a standard spot labor market analysis). Any increase in equilibrium labor input increases aggregate output, leading to a rise in the productive externality. The estimated externality elasticity is enormous in this special case $\left(\phi_{2}=0.87\right)$. Recalling that agents view the externality parametrically, labor demand shifts out due to the increase in productivity. In labor market equilibrium, labor productivity and the spot wage increase 2.5 percent in the fourth quarter, while labor hours increase a mere 0.4 percent. Apparently, the equilibrium labor demand relationship is upward sloping in this case. ${ }^{22}$ The intuition regarding investment's fourth quarter collapse requires looking forward to the first quarter. In this perfect foresight equilibrium, agents can see that the marginal product of capital will be quite low in the first quarter because the externality will be low (and this is taken parametrically). Consequently, fourth quarter investment demand falls. In equilibrium, the increase in consumption demand is fulfilled partly by an increase in output and partly by a reduction in investment demand; the interest rate does not need to increase in this case.

\section{B. Labor Hoarding Only}

Figure 3 indicates that the labor hoarding only specification has the same problems. The growth rate of output, the Solow residual and productivity increase monotonically from season one through season four whereas the data for these variables shows an up down pattern. Once again the pattern of investment is the reverse of what we see in the data while the fit of consumption is pretty good.

The intuition for the labor hoarding only case also begins in the labor market. The estimated Christmas demand shift (8.8 percent) is substantially larger than the baseline $(2.2$ percent) and increasing returns only (4.4 percent) cases. This shifts labor supply out and 
to the right by a large amount. Increases in labor hours lead to increases in the marginal product of labor effort, so that labor effort increases, too. The equilibrium effect is to shift out the marginal product of labor hours, also. In equilibrium labor hours and labor productivity increase by similar amounts, while the shadow value of labor hours $(1-\theta) y / n v$ actually decreases due to the larger shift in labor supply. The intuition for the collapse of fourth quarter investment is similar to the increasing returns only case: in perfect foresight equilibrium, agents see that the first quarter will be a time when the marginal product of capital is low. In equilibrium, the fourth quarter increase in consumption demand is satisfied partly by a larger increase in output than in the increasing returns only case; however, an equilibrium reduction investment is still required at a fourth quarter higher interest rate.

\section{Baseline Reconciliation}

In light of the case analyses above, the baseline specification is able to generate an increase in fourth quarter investment due to a larger increase in output than for the labor hoarding only case. The fourth quarter Christmas demand shift expands labor supply a bit less than in the labor hoarding only case, but the externality expands further as labor effort expands, too. In labor market equilibrium the shadow wage for labor hours falls by only 0.2 percent. The equilibrium expansion in output is large enough to more than satisfy the increase in consumption demand; consequently, interest rates decline, and an increase in investment occurs in spite of the negative first quarter effects on the marginal product of capital.

\section{Limitations of the Analysis}

Our analysis indicates that both labor hoarding and increasing returns are important mechanisms for reconciling seasonal comovements in aggregate data. The finding that increasing returns is important for explaining these fluctuations sets our analysis apart from many other recent studies that have found evidence of constant returns to scale in manufacturing data (see for example, Burnside 1996 for a review of this literature). This section considers some of the limitations of our analysis. A particular question of interest is whether

our finding of increasing returns might be standing in for some other feature of the economy that we have abstracted from. At the outset it is important to note that if it were possible 
for equilibrium variations in labor effort to generate sufficiently large seasonal movements in output, the estimates of $\phi_{2}$ would be much closer to zero. We have experimented with alternative specifications of preferences and have not found a case where labor hoarding alone is able to reproduce the principal features of seasonality in the data. While this is ultimately an empirical question, the analysis of the previous section suggests that labor demand shifters help. This is the role played by increasing returns.

It is possible that other features of the economy we have left unmodeled could induce a similar type of demand response. For instance, our model assumes that the capital stock is utilized fully in production: alternatively, the utilization of capital could be less than 100 percent varying both cyclically and seasonally. Such a specification could increase effective capital input in the fourth quarter thereby shifting the labor demand schedule out. While incorporating capital utilization into the model could in principle magnify the demand stimulus with less increasing returns, other seasonal anomalies might emerge. For example, recent efforts to model endogenous variations in capital utilization have assumed that capital depreciates more rapidly when it is used intensively. In this environment, increasing returns might be unnecessary since firms could meet a high fourth quarter demand for goods by utilizing both labor effort and capital more intensively. High levels of fourth quarter production would lead to high marginal costs of producing investment goods in the fourth quarter. With capital depreciating more rapidly in the fourth quarter, the demand for investment goods should be high. Since consumption demand will be lower in the first quarter, the first quarter would be a good time to produce investment goods. This partial equilibrium intuition leads to a predicted low fourth quarter investment rate, and a high first quarter investment rate; but this is the opposite of the data's seasonals.

Another potential explanation for our finding of increasing returns is that it is spurious and due instead to data measurement problems. For example, the output data may be mismeasured cyclically and seasonally. Analyzing plant-level manufacturing data, Aizcorbe and Kozicki (1995) find that plants which are shut-down completely (losing all measured output) continue to employ some labor. In this case, plant-level productivity falls dramatically. If workers are performing valuable work, such as maintenance or retooling, then investment output during this period may be missing from the measured data. ${ }^{23}$ Taken at face value, 
this argument suggests that output is probably smoother over the seasonal cycle than the data indicate. This could reduce the importance of increasing returns in matching the data's facts.

Finally, our analysis assumes that an aggregate production function is an inherently interesting object of study. However, Basu and Fernald (1995) argue that industry technology structures may not aggregate consistently over the business cycle to time-invariant production structures. In this case, a more appropriate analysis must begin with a sectoral model of production.

\section{Conclusion}

This paper demonstrates that the seasonal cycle contains potentially valuable information for uncovering the roles of labor hoarding and increasing returns. In contrast to business cycles which are arguably induced by both demand and technology shocks of varying persistence, seasonal fluctuations are anticipated, transient, and easily identified with calendar events like Christmas. Our findings indicate that increasing returns to scale alone does not directly explain the seasonality in measured Solow residuals. However, it plays an important role in magnifying small variations in work effort. Hall (1988) has argued that labor hoarding requires implausibly large variations in work effort to explain cyclical fluctuations in Solow residuals. For seasonal fluctuations this is not the case. Our estimated parameterization implies labor effort variation of no more than 5 percent on a quarterly basis. With increasing returns these variations are magnified, thereby producing fluctuations in total factor productivity that are of the same magnitude observed in the data. Finally, since our explanation rests on phenomena which are not country-specific-Christmas celebrations, productive externalities, and labor hoarding - this model may offer an explanation for the similar cross-country seasonal patterns documented by Beaulieu and Miron (1992). 


\section{Notes}

${ }^{1}$ More generally seasonal fluctuations have proved to be a valuable source of identification in a number of other studies including Ghysels (1988), and Cecchetti, Kashyap and Wilcox (1994).

${ }^{2}$ Our use of seasonal identifying restrictions is similar to Bernanke and Parkinson's analysis. Using interwar data, Bernanke and Parkinson (1991) investigate procyclical productivity in industrial markets. Under the plausible identifying assumption that the Great Depression was not caused by a series of large technology shocks, they find evidence in favor of increasing returns and labor hoarding.

${ }^{3}$ In Burnside-Eichenbaum-Rebelo (1993), the impulse response functions of labor effort to innovations in technology and government purchases appear to be zero after the initial period's response.

${ }^{4}$ We also estimated variants of our model where the disutility of labor effort was specified as $-\xi \ln \left(v_{t}\right)$, and the model's seasonal implications were similar to the ones reported for the quadratic specification.

${ }^{5}$ Alternatively, if $z_{t}$ were deleted from the specification of $\phi_{t}$ in (7), the externality would grow with economywide output, and this would be global increasing returns. Given our econometric methodology in Section 3, these two specifications are observationally equivalent. Specifically, for local IR all growth is exogenous; whereas for global IR the exogenous growth is magnified by the $\phi_{t}$ process so that some growth is endogenous. In the global case, there is a lower value of $\lambda$ which interacts with the same value of $\phi_{2}$ as in the local case to produce the same equilibrium as we report in Section 4. Applying our estimation procedure to the global case would produce this lower value of $\lambda$.

${ }^{6}$ Due to the inclusion of the growth term in $J_{t}$, the nonseasonal steady state of this economy will be the same as an economy which omits adjustment costs. Besides being plausible, the growth term allows greater comparability with previous studies.

${ }^{7}$ This is a solution strategy previously employed by Romer (1986).

${ }^{8}$ For example, see King, Plosser, and Rebelo (1988) for a standard definition of a balanced growth path.

${ }^{9}$ For an explicit characterization of this type of seasonal equilibrium path, see Braun 
and Evans (1995) or Chatterjee and Ravikumar (1992).

${ }^{10}$ We assume that $S_{t}$ is an attempt to measure $\Delta \log z_{t}$ rather than $(1-\theta) \Delta \log z_{t}$.

${ }^{11}$ Evans (1992) documents that Prescott's measure of the Solow residual is not exogenous when seasonally adjusted data is used. The finding that money, interest rates, and government spending Granger-cause Prescott's residual could be due to increasing returns or unobserved variations in labor effort of the form modeled here.

${ }^{12}$ This normalization ensures that the average labor input in the model corresponds to the average level of labor hours in the data.

${ }^{13} \mathrm{We}$ are assuming in our estimation that the following variables are stationary: $y / c, y / k$, $y / i, n$, and the growth rates of $y, c, k, i$, and $n$.

${ }^{14}$ Hall (1988) has noted that his set of instruments would fail to be exogenous in this setting.

${ }^{15}$ On the other hand, Constantinides and Ferson (1991) find evidence of habit-persistence in consumption goods preferences $(a<0)$. In simulations of an equilibrium business cycle model with seasonality, Braun and Evans (1995) found that durability in consumption $(a>0)$ helped the model match key business cycle moments better than habit-persistence.

${ }^{16}$ See Braun and Evans for a more detailed discussion of the role of local durability in consumption for propagating demand shocks.

${ }^{17}$ Ghysels (1988) observes that there is a lot of spectral power at seasonal frequencies for identifying adjustment cost parameters.

${ }^{18}$ Barsky and Miron also find that there is statistically significant seasonality in the real interest rate although the magnitude of the estimated seasonals (in levels) is small.

${ }^{19}$ The model's predicted seasonal growth rates are a highly nonlinear function of the estimated structural parameter vector $\hat{\psi}$. The asymptotic covariance of the predicted seasonals is computed using the covariance estimator of $\hat{\psi}$ and the gradient of the nonlinear function. The Wald statistics are constructed from these objects in the usual way.

${ }^{20}$ Although many of the seasonal patterns in the data appear to differ from the model's implications, most notably investment, the LaGrange multiplier tests indicate that these differences are not significant. If one ignores the covariance between these two estimates, some of these estimates also appear to be different. Evidently, the covariances are important 
for statistical inference in this case.

${ }^{21}$ The fourth quarter growth rate of labor effort is only 4 percent.

${ }^{22}$ See Aiyagari (1995) for a discussion of this issue.

${ }^{23}$ This economic issue is similar to the home production literature which implies that market output measures seriously understate the cyclical movements in economic activity; for example, see Benhabib, Rogerson, and Wright (1991) and Greewood and Hercowitz (1991). 


\section{References}

Aiyagari, S. Rao. 1995. The econometrics of indeterminancy: An applied study: A comment. Carnegie Rochester Conference Series on Public Policy 43, 273-84.

Aizcorbe, Ana, and Kozicki, Sharon. 1995. The comovement of output and labor productivity in aggregate data for auto assembly plants. Finance and Economics Discussion Series 95-33. Board of Governors of the Federal Reserve System.

Barsky, R., and Miron, J. 1989. The seasonal cycle and the business cycle. Journal of Political Economy.

Basu, S., and Fernald, J. 1995. Are apparent productive spillovers a figment of specification error? Journal of Monetary Economics 36 (1): 165-88.

Baxter, M., and King, R. 1990. Productive externalities and cyclical volatility. Working Paper 245. Rochester Center for Economic Research.

Beaulieu, J., and Miron, J. 1992. A cross country comparison of seasonal cycles and business cycles. Economic Journal 102 (413): 772-88.

Benhabib, J.; Rogerson, R.; and Wright, R. 1991. Homework in macroeconomics: Household production and aggregate fluctuations. Journal of Political Economy 99 (6): 1166-87.

Bernanke, B., and Parkinson, M. 1991. Procyclical labor productivity and competing theories of the business cycle: Some evidence from interwar U.S. manufacturing industries. Journal of Political Economy 99 (3): 439-59.

Braun, R. 1994. Tax disturbances and real activity in the postwar United States. Journal of Monetary Economics 33 (3): 441-62.

Braun, R., and Evans, C. 1995. Seasonality and equilibrium business cycle theories. Journal of Economic Dynamics and Control 19 (3): 503-31.

Bryant, J. 1983. A simple rational expectations Keynes-type model. Quarterly Journal of Economics 97: 525-29.

Burnside, Craig. 1996. Production function regressions, returns to scale, and externalities. Manuscript. World Bank.

Burnside, C.; Eichenbaum, M.; and Rebelo, S. 1993. Labor hoarding and the business cycle. Journal of Political Economy 101 (2): 245-73. 
Burnside, C.; Eichenbaum, M.; and Rebelo, S. 1995. Capital utilization and returns to scale. NBER Macroeconomics Annual 1995. Cambridge, Ma.: MIT Press.

Caballero, R., and Lyons, R. 1992. External effects in U.S. procyclical productivity. Journal of Monetary Economics 29 (2): 209-25.

Chatterjee, S., and Ravikumar, B. 1992. A neoclassical model of seasonal fluctuations. Journal of Monetary Economics 29 (1): 58-86.

Cecchetti, Stephen C.; Kashyap, Anil K.; and Wilcox, David W. 1994. Why firms smooth the seasonal in production during a boom. Manuscript. Ohio State University.

Christiano, L., and Eichenbaum, M. 1992. Current real business cycle theories and aggregate labor market fluctuations. American Economic Review 82 (3): 430-50.

Chirinko, R. 1995. Non-convexities, labor hoarding, technology shocks, procyclical productivity: A structural econometric approach. Journal of Econometrics 66 (1-2): 61-98.

Constantinides, G., and Ferson, W. 1991. Habit persistence and durability in aggregate consumption: Empirical tests. Journal of Financial Economics 29 (2): 199-240.

Cooper, R., and Haltiwanger, J. 1992. Macroeconomic implications of production bunching: Factor and final demand linkages. Journal of Monetary Economics 30 (1): 107-27.

Cooper, R., and Haltiwanger, J. 1996. Evidence on macroeconomic complementarities. Review of Economics and Statistics 78 (1): 78-93.

Diamond, P. 1982. Aggregate demand management in search equilibrium. Journal of Political Economy 90 (5): 881-94.

Eichenbaum, M., and Hansen, L. 1990. Estimating models with intertemporal substitution using aggregate time series data. Journal of Business and Economic Statistics.

Eichenbaum, M.; Hansen, L.; and Singleton, K. 1989. A time series analysis of representative agent models of consumption and leisure choice under uncertainty. Quarterly Journal of Economics.

Eichenbaum, M.; Hansen, L.; and Singleton, K. 1984. Appendix to: A time series analysis of representative agent models of consumption and leisure choice under uncertainty. Manuscript. Carnegie-Mellon University.

Evans, C. 1992. Productivity shocks and real business cycles. Journal of Monetary Economics 29 (2): 291-308. 
Gallant, R.; Hansen, L.; and Tauchen, G. 1990. Using conditional moments of asset payoffs to infer the volatility of intertemporal marginal rates of substitution. Journal of Econometrics.

Gallant, R., and Tauchen, G. 1989. Seminonparametric estimation of conditionally constrained heterogeneous processes: Asset pricing applications. Econometrica 57, 10911120.

Ghysels, E. 1988. A study toward a dynamic theory of seasonality for economic time series. Journal of American Statistical Association 83, 168-72.

Ghysels, E. 1991. On the economics and econometrics of seasonality. Manuscript. University of Montreal.

Greenwood, J., and Hercowitz, Z. 1991. The allocation of capital and time over the business cycle. Journal of Political Economy 99 (6): 1188-214.

Hall, R. 1988. The relation between price and marginal cost in U.S. industry. Journal of Political Economy 96, 921-47.

Hall, R. 1989. Temporal agglomeration. Working Paper 3143. NBER.

Hansen, L. 1982. Large sample properties of generalized method of moments estimators. Econometrica 50, 1029-54.

Hansen, L., and Sargent, T. 1993. Seasonality and approximation errors in rational expectations models. Journal of Econometrics 55 (1-2): 21-55.

Hansen, L., and Singleton, K. 1982. Generalized instrumental variables estimation of nonlinear rational expectations models. Econometrica 50, 1269-86.

Heaton, J. 1988. The interaction between time-nonseparable preferences and time aggregation. Manuscript. University of Chicago.

Howitt, P. 1985. Transactions costs in the theory of unemployment. American Economic Review 75 (1): 88-100.

King, R.; Plosser, C.; and Rebelo, S. 1988. Production, growth, and business cycles: I. The basic neoclassical model. Journal of Monetary Economics 21 (213): 195-232.

Kydland, F., and Prescott, E. 1982. Time to build and aggregate fluctuations. Econometrica $50,1345-70$. 
Murphy, K.; Shleifer, A.; and Vishny, R. 1989. Building blocks of market clearing business cycle models. NBER Macroeconomics Annual, 247-87.

Newey, W., and West, K. 1987a. A simple, positive definite, heteroskedasticity and autocorrelation consistent covariance matrix. Econometrica 55, 703-08.

Newey, W., and West, K. 1987b. Hypothesis testing with efficient method of moments estimators. International Economic Review 28, 777-88.

Prescott, E. 1986. Theory ahead of business cycle measurement. Carnegie-Rochester Conference Series on Public Policy 27 (Autumn): 11-44.

Ramey, V. 1991. Nonconvex costs and the behavior of inventories. Journal of Political Economy.

Romer, P. 1986. Increasing returns and long-run growth. Journal of Political Economy 94 (5): 1002-37.

Romer, P. 1988. Capital accumulation in the theory of long-run growth. In Modern Business Cycle Theory, ed. Robert Barro, pp. 51-127. Harvard University Press.

Rotemberg, J., and Summers, L. 1990. Inflexible prices and procyclical productivity. Quarterly Journal of Economics 105 (4): 851-74.

Sims, C. 1993. Rational expectations modeling with seasonally adjusted data. Journal of Econometrics 55 (1-2): 9-19.

Singleton, K. 1988. Econometric issues in the analysis of equilibrium business cycle models. Journal of Monetary Economics. 
Table 1

GMM Parameter Estimates

\begin{tabular}{lrc}
\hline \hline Parameter & Estimate & Standard Error* \\
\hline$\theta$ & .2792 & .00155 \\
$\bar{\tau}$ & .2354 & .00073 \\
$\tau_{4}$ & .2407 & .00080 \\
$\lambda$ & .0021 & .00010 \\
$\psi_{1}$ & 27.656 & 3.05715 \\
$\psi_{2}$ & .2377 & .04996 \\
$a$ & .4423 & .01018 \\
$b$ & -.5284 & .01275 \\
$\phi_{2}$ & .2170 & .09332 \\
$\xi$ & .0158 & .03410 \\
& & \\
$\mathrm{~J}$-Statistic & 28.51 & \\
Degrees of Freedom & 24 & \\
$\mathrm{P}$-Value & $.2392)$ & \\
\hline \hline
\end{tabular}

*A Newey-West procedure (1987a) with four lags was used to compute the optimal GMM weighting matrix. 
Table 2

Hypothesis Test Results

(1) $\Delta x_{t}=d^{\prime} q_{t}+w_{t} \quad \mathrm{H}_{0}^{d}:$ The data do NOT exhibit deterministic seasonality. The elements of $d$ are equal.

(2) $\Delta x_{t}=f(\psi)^{\prime} q_{t}+w_{t} \quad \mathrm{H}_{0}^{d}$ : The model does NOT exhibit deterministic seasonality. The element of $f(\psi)$ are equal.*

(3) $f(\psi)=d$

$\mathrm{H}_{0}^{d}$ : The model's predicted seasonality equals the data's seasonality.

\begin{tabular}{|c|c|c|c|}
\hline Variable X & $\mathrm{H}_{0}^{d \dagger}$ & $\mathrm{H}_{0}^{f}$ & $\mathrm{H}_{0}^{j \ddagger}$ \\
\hline Solow & $\begin{array}{l}472.7 \\
(.000)\end{array}$ & $\begin{array}{r}4646 \\
(.000)\end{array}$ & $\begin{array}{r}.765 \\
(.943)\end{array}$ \\
\hline Output & $\begin{array}{c}842.4 \\
(.000)\end{array}$ & $\begin{array}{r}5856 \\
(.000)\end{array}$ & $\begin{array}{r}.896 \\
(.925)\end{array}$ \\
\hline Consumption & $\begin{array}{r}2077 \\
(.000)\end{array}$ & $\begin{array}{r}7541 \\
(.000)\end{array}$ & $\begin{array}{r}.233 \\
(.994)\end{array}$ \\
\hline Investment & $\begin{array}{r}108.6 \\
(.000)\end{array}$ & $\begin{array}{r}160.2 \\
(.000)\end{array}$ & $\begin{array}{r}.260 \\
(.992)\end{array}$ \\
\hline Capital & $\begin{array}{r}34.57 \\
(.000)\end{array}$ & $\begin{array}{r}160.8 \\
(.000)\end{array}$ & $\begin{array}{r}.233 \\
(.994)\end{array}$ \\
\hline Labor Hours & $\begin{array}{r}1414 \\
(.000)\end{array}$ & $\begin{array}{r}540.6 \\
(.000)\end{array}$ & $\begin{array}{r}1.824 \\
(.768)\end{array}$ \\
\hline Labor Effort & - & $\begin{array}{r}6796 \\
(.000)\end{array}$ & - \\
\hline Labor Prod. & $\begin{array}{c}330.14 \\
(.000)\end{array}$ & $\begin{array}{r}3564 \\
(.000)\end{array}$ & $\begin{array}{r}1.860 \\
(.762)\end{array}$ \\
\hline Real Rate & $\begin{array}{r}11.78 \\
(.019)\end{array}$ & $\begin{array}{r}318.01 \\
(.000)\end{array}$ & $\begin{array}{r}.038 \\
(.999)\end{array}$ \\
\hline
\end{tabular}


*Equation (2) is predicted by our theoretical model, but our test is not regressionbased. See the text for a description.

†For both columns 1 and 2, the Wald test statistics are asymptotically distributed

$x^{2}$ with four degrees of freedom. The numbers in parentheses are probability values of the test statistic.

$\ddagger$ The Lagrange Multiplier test statistic is asymptotically distributed $x^{2}$ with four degrees of freedom. 
Table 3

Seasonal Growth Rates*

\begin{tabular}{|c|c|c|c|c|c|}
\hline Variable & Season & Model & Std. Error & Data & Std. Error \\
\hline \multirow[t]{4}{*}{ Solow Residual } & Winter & -7.439 & $(.154)$ & -5.919 & $(.399)$ \\
\hline & Spring & 3.470 & $(.091)$ & 2.193 & $(.396)$ \\
\hline & Summer & -.654 & $(.129)$ & .019 & $(.484)$ \\
\hline & Fall & 5.463 & $(.100)$ & 4.060 & $(.428)$ \\
\hline \multirow[t]{4}{*}{ Output } & Winter & -6.485 & $(.126)$ & -6.348 & $(.208)$ \\
\hline & Spring & 2.884 & $(.094)$ & 3.460 & $(.235)$ \\
\hline & Summer & -.299 & $(.107)$ & -.672 & $(.111)$ \\
\hline & Fall & 4.740 & $(.090)$ & 3.248 & $(.182)$ \\
\hline \multirow[t]{4}{*}{ Consumption } & Winter & -6.728 & $(.123)$ & -6.540 & $(.300)$ \\
\hline & Spring & 3.459 & $(.088)$ & 2.815 & $(.328)$ \\
\hline & Summer & -1.276 & $(.078)$ & .423 & $(.302)$ \\
\hline & Fall & 5.385 & $(.067)$ & -4.730 & $(.385)$ \\
\hline \multirow[t]{4}{*}{ Investment } & Winter & -5.620 & $(.527)$ & -8.702 & $(1.092)$ \\
\hline & Spring & .817 & $(.110)$ & 5.492 & $(.900)$ \\
\hline & Summer & 3.182 & $(.370)$ & -.081 & $(.659)$ \\
\hline & Fall & 2.461 & $(.517)$ & 3.745 & $(1.121)$ \\
\hline \multirow[t]{4}{*}{ Capital } & Winter & .301 & $(.012)$ & .596 & $(.115)$ \\
\hline & Spring & .141 & $(.011)$ & .348 & $(.097)$ \\
\hline & Summer & .158 & $(.011)$ & .498 & $(.103)$ \\
\hline & Fall & .240 & $(.015)$ & .476 & $(.086)$ \\
\hline \multirow[t]{4}{*}{ Labor Hours } & Winter & -1.675 & $(.074)$ & -3.112 & $(.156)$ \\
\hline & Spring & .477 & $(.053)$ & 2.473 & $(.165)$ \\
\hline & Summer & .178 & $(.026)$ & .720 & $(.127)$ \\
\hline & Fall & 1.021 & $(.057)$ & .262 & $(.156)$ \\
\hline \multirow[t]{4}{*}{ Labor Prod. } & Winter & -4.810 & $(.117)$ & -3.229 & $(.264)$ \\
\hline & Spring & 2.407 & $(.055)$ & .987 & $(.295)$ \\
\hline & Summer & -.477 & $(.087)$ & -.048 & $(.346)$ \\
\hline & Fall & 3.719 & $(.074)$ & 2.986 & $(.335)$ \\
\hline \multirow[t]{4}{*}{ Change in Real Rate } & Winter & 2.812 & $(.214)$ & -1.079 & $(.344)$ \\
\hline & Spring & .822 & $(.178)$ & .318 & $(.392)$ \\
\hline & Summer & .397 & $(.141)$ & .823 & $(.297)$ \\
\hline & Fall & -4.031 & $(.274)$ & -.047 & $(.299)$ \\
\hline
\end{tabular}


*Quarterly rates of growth in percentages, except for the real interest rate which is the quarterly change in annualized yields (that is, $\Delta \log \left(1+r_{t}\right)$, with $r_{t}$ at annual rates). 
Table 4

Seasonal Growth Rates: Case Analysis*

\begin{tabular}{|c|c|c|c|}
\hline "Variable & Season & 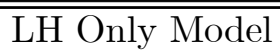 & IR Only Model \\
\hline \multirow[t]{4}{*}{ Solow Residual } & Winter & -3.021 & -3.988 \\
\hline & Spring & -1.119 & -1.180 \\
\hline & Summer & .902 & 2.756 \\
\hline & Fall & 3.868 & 3.481 \\
\hline \multirow[t]{4}{*}{ Output } & Winter & -3.336 & -3.205 \\
\hline & Spring & -1.424 & -.914 \\
\hline & Summer & 1.125 & 2.298 \\
\hline & Fall & 4.264 & 2.890 \\
\hline \multirow[t]{4}{*}{ Consumption } & Winter & -5.137 & -6.153 \\
\hline & Spring & -1.137 & 1.413 \\
\hline & Summer & -.061 & .145 \\
\hline & Fall & 6.964 & 5.664 \\
\hline \multirow[t]{4}{*}{ Investment } & Winter & 2.877 & 7.056 \\
\hline & Spring & -2.381 & -8.898 \\
\hline & Summer & 5.005 & 9.711 \\
\hline & Fall & -4.872 & -6.799 \\
\hline \multirow[t]{4}{*}{ Capital } & Winter & .104 & .186 \\
\hline & Spring & .177 & .376 \\
\hline & Summer & .109 & .122 \\
\hline & Fall & .240 & .385 \\
\hline \multirow[t]{4}{*}{ Labor Hours } & Winter & -1.744 & -.565 \\
\hline & Spring & -.970 & -.246 \\
\hline & Summer & .646 & .407 \\
\hline & Fall & 2.068 & .404 \\
\hline \multirow[t]{4}{*}{ Labor Prod. } & Winter & -1.592 & -2.640 \\
\hline & Spring & -.454 & -.668 \\
\hline & Summer & .480 & 1.891 \\
\hline & Fall & 2.196 & 2.486 \\
\hline \multirow[t]{4}{*}{ Change in Real Rate } & Winter & -.959 & -.747 \\
\hline & Spring & 1.162 & .963 \\
\hline & Summer & -.826 & -.223 \\
\hline & Fall & .623 & .007 \\
\hline J-statistic & & 6361 & 1569 \\
\hline Degree of Freedom & & 25 & 26 \\
\hline $\mathrm{P}$-value & & .000 & .000 \\
\hline
\end{tabular}


*Quarterly rates of growth in percentages, except for the real interest rate which is the quarterly change in annualized y 
Solow Residual

QUARTERLY RATES OF GROWTH

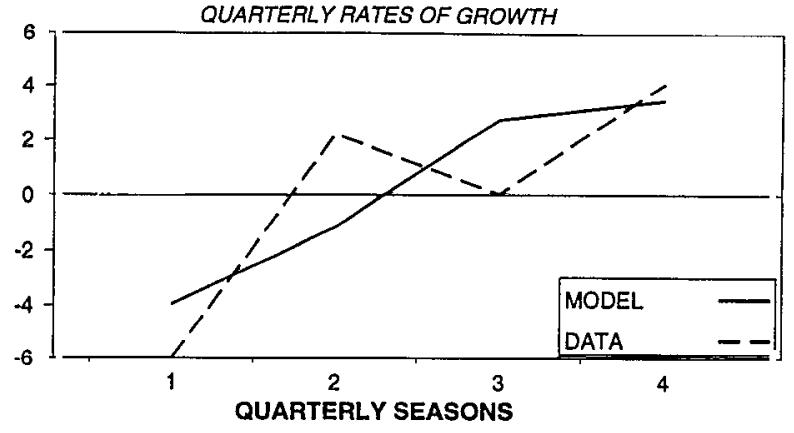

Consumption

QUARTERLY RATES OF GROWTH

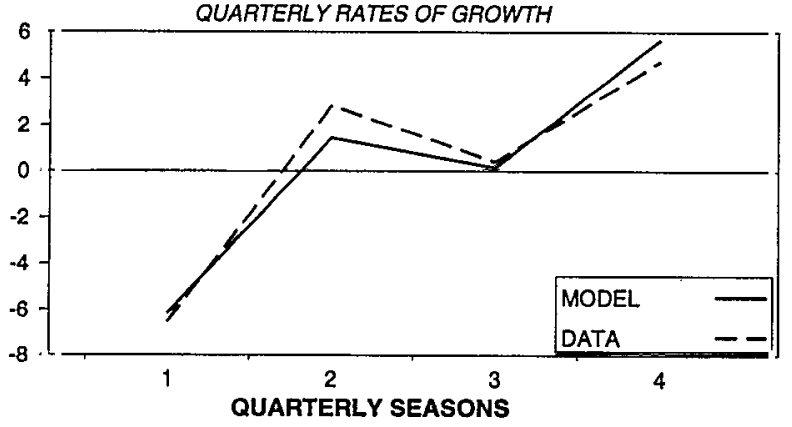

Output

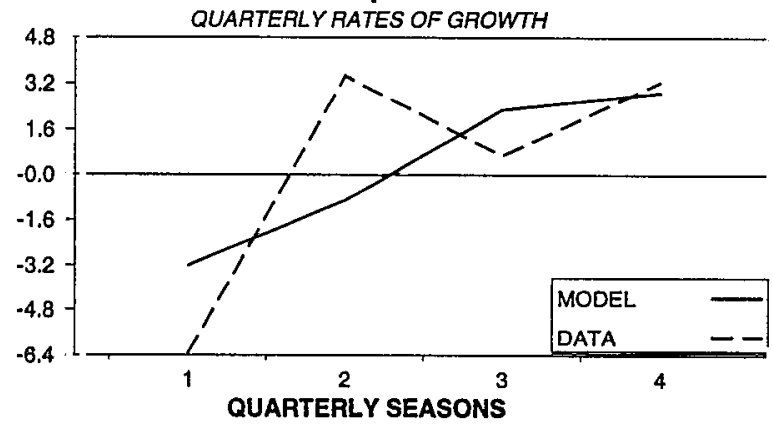

Investment

QUARTERLY RATES OF GROWTH

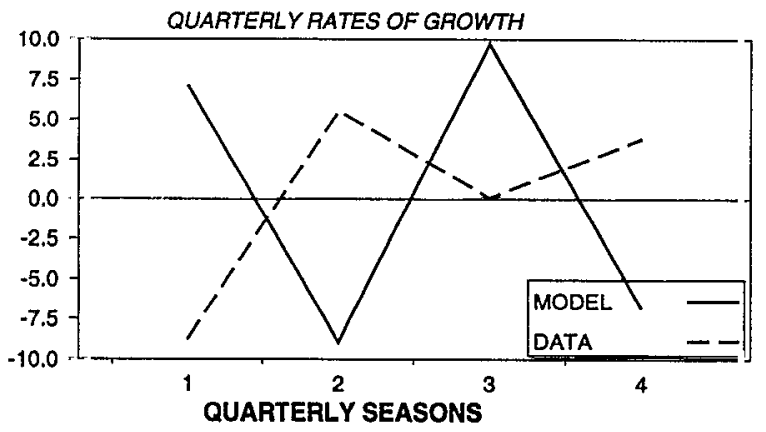

Labor Hours

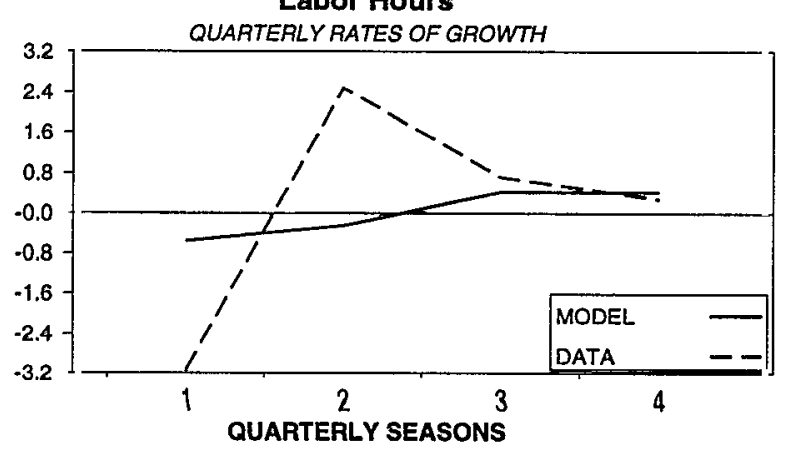

Unobserved Labor Effort Percent Deviations

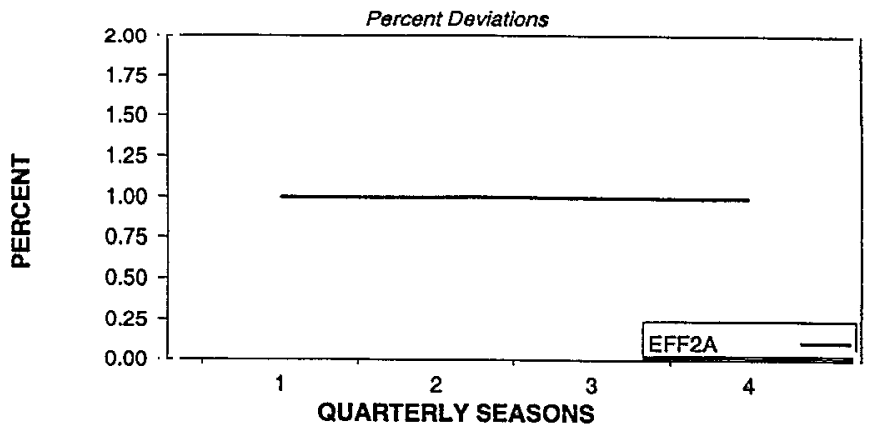

Labor Productivity

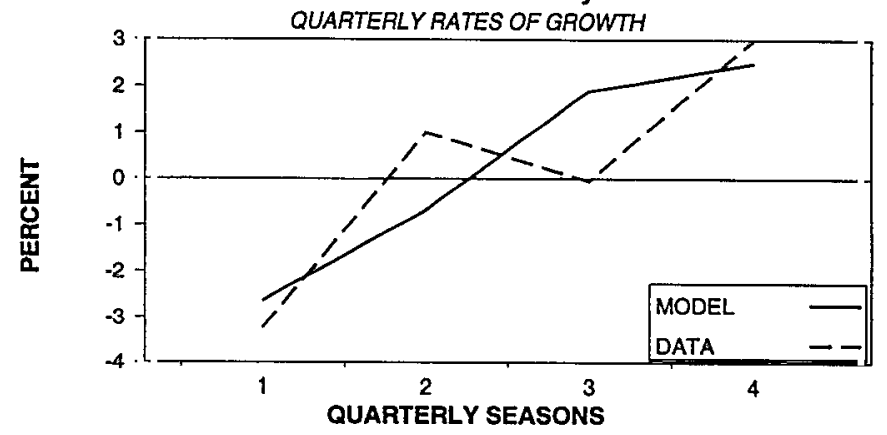

Capital Stock

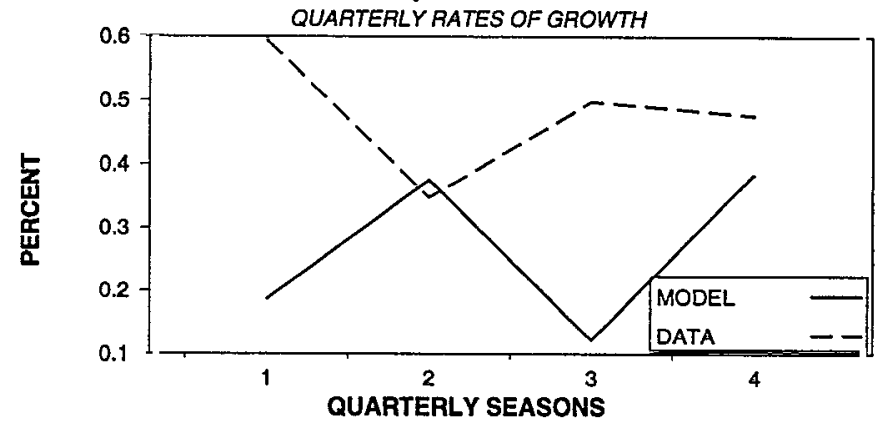

Real Interest Rate

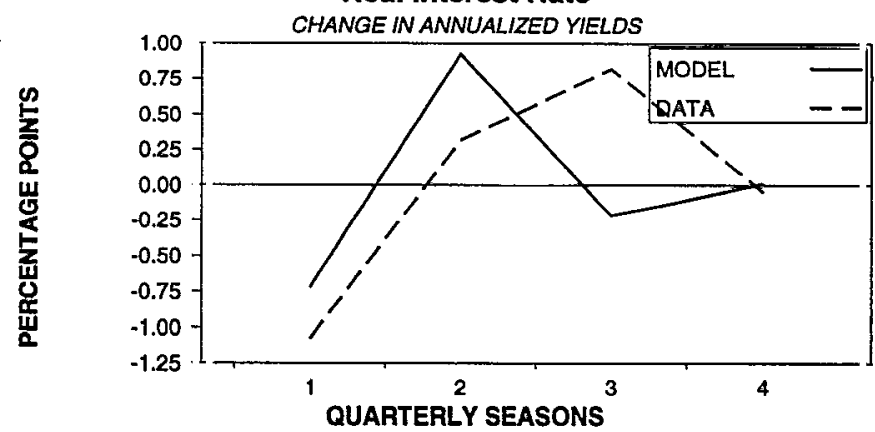


Solow Residual

QUARTERLY RATES OF GROWTH

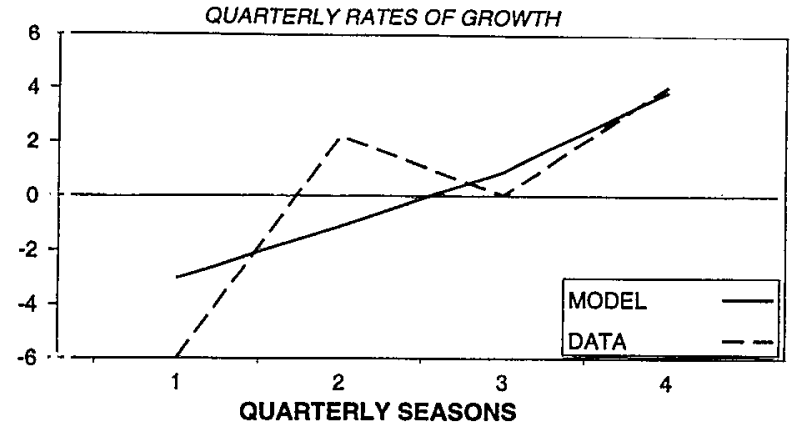

Consumption

QUARTERLY RATES OF GROWTH

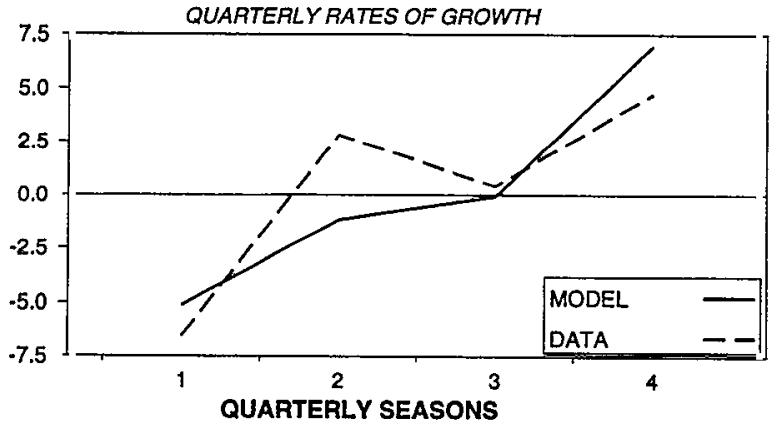

Output

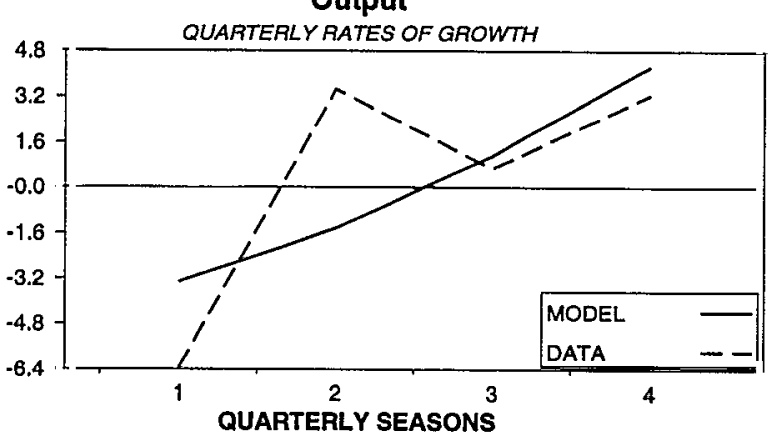

Investment

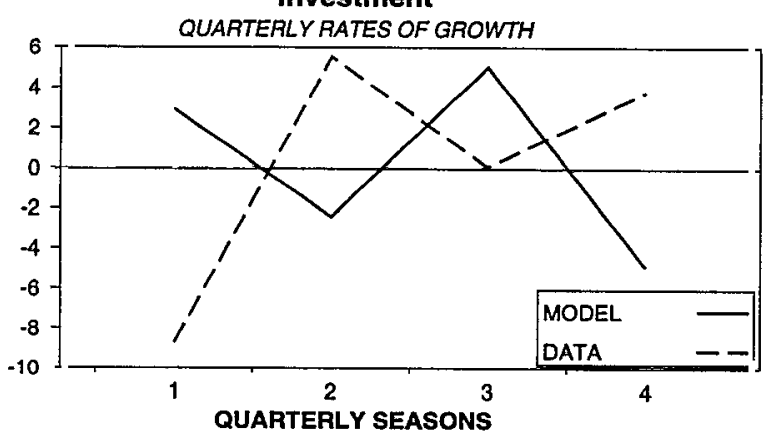

Labor Hours

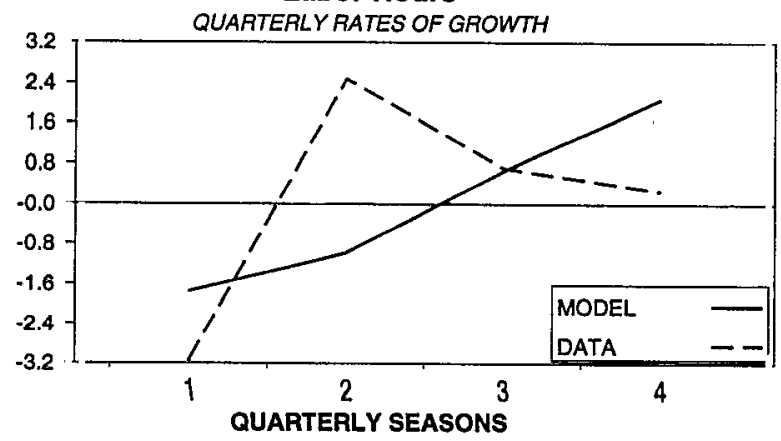

Unobserved Labor Effort

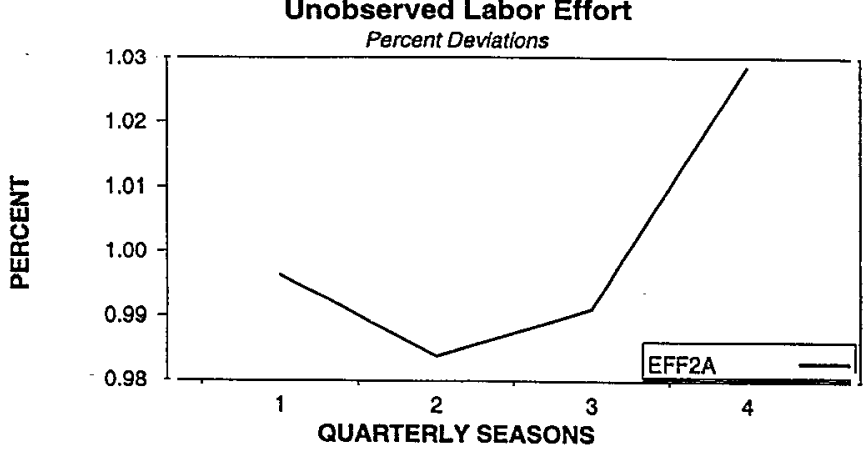

Labor Productivity

QUARTERLY RATES OF GROWTH

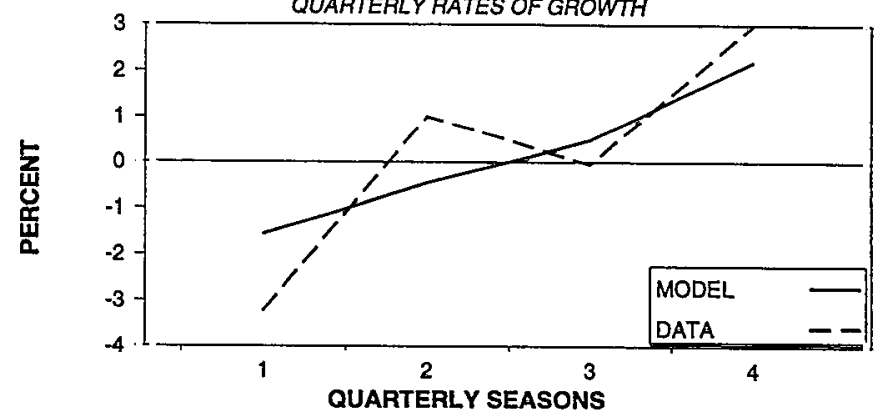

Capital Stock
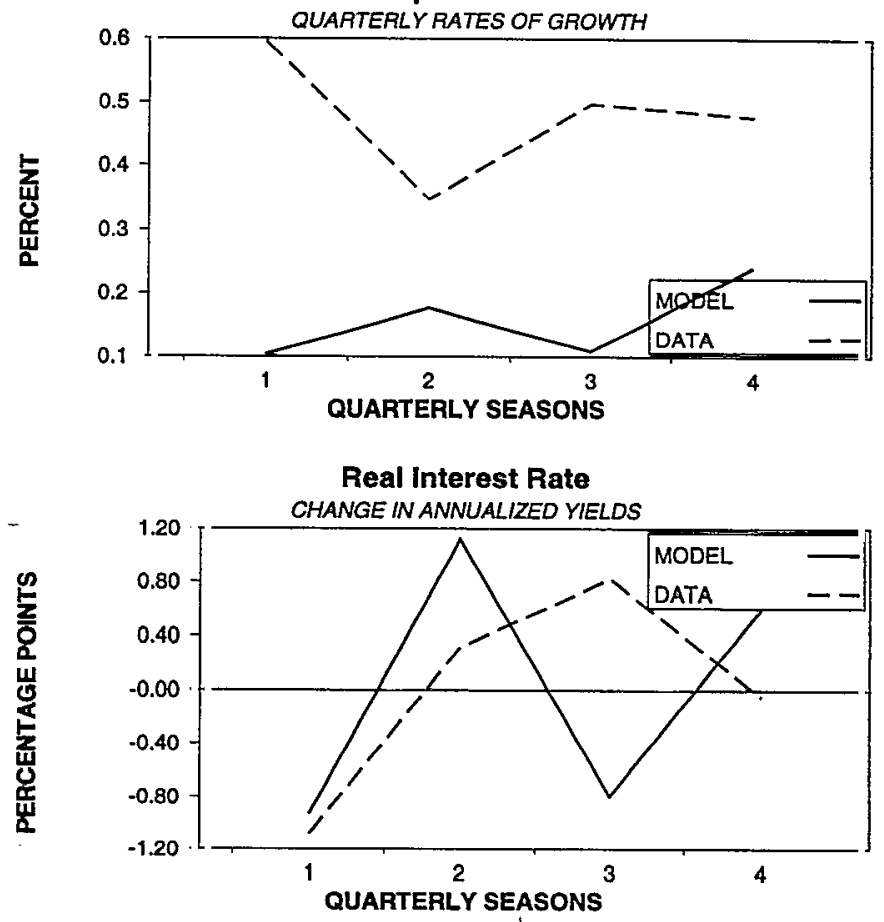